\title{
A Proposed Quality Assurance Intelligent Model for Higher Education Institutions in Saudi Arabia
}

\author{
Abdelmonim M. Artoli, Hassan I. Mathkour, and Alaaeldin M. Hafez \\ College of Computer and Information Systems \\ , King Saud University \\ Saudi Arabia \\ Emails: binmathkour@yahoo.com, aartoli@ksu.edu.sa, ahafez@ksu.edu.sa
}

\begin{abstract}
Recent growth and demands for dealing with increasing complexity in management, evaluation and accreditation of higher educational institutions have led keynote academic institutions and higher education authorities to adopt and try nonconventional solutions known to business firms to account for massive data management. The development in new practices and emerging technology for analytics and information management have offered different solutions such as data warehousing, big data and business intelligence. Such solutions are gradually being installed in a number of renown universities. Due to the difference between the two firms (higher education and buisness industry) in nature and aims, tailor-made soultions are needed.

This paper shares authors' experience in designing and implementing an educational information system in the College of Computers and Information systems at King Saud University, Saudi Arabia. The paper also highlights differences between educational intelligence and business intelligence systems. Higher education implementation aspects ensuring suitable data query service to ease the running of high educational institutions are discussed and recognized.
\end{abstract}

Keywords: Higher Education Information Systems, Educational Intelligence, Business Intelligence, Data Warehousing cloud computing.

\section{Introduction}

Business Intelligence is a concept of applying a set of technologies to turn data into meaningful information [1]. In higher educational institutions, huge amount of data is produced on daily basis. This has raised high demand for devising intelligent solutions that could handle documenting, retrieving and analyzing of highly complex data clusters. The set of technologies used in educational institutions to account for data management are similar to those used by business firms, such as Big Data, data warehouses and OLAP tools. However, certain concerns at the planning level need to be considered and case-specific solutions are unavoidable. 
With Business intelligence applications, large amounts of data originating in desired formats can be consolidated to provide timely intelligent information that is easily understood and directly of use. This controls and enable change management in the organization and drives strategy development toward higher profits. The story may differ at the higher education institutions since profit is not an objective and quality is not tolerated.

Numerous solutions have been used in handling big repository of data clusters in higher education institutes [2-6] which are mainly adopted from business intelligence solutions. The difficulty in applying business intelligence solutions in higher education environments is attributed to the nature of data collected, procedures conducted, and knowledge extracted. In a typical business intelligence environment the objectives are to extract information related to customer satisfaction, performance measurements and profit maximization. On the other hand, educational managers are interested in meeting educational quality requirements through rubrics, measuring performance and archiving of student data over the years. Key performance indicators for the two systems are similar in the tools they are using but different in the impact on the management process. They are concerned with multi-dimensional high quality useful information as well as case-specific time-dependent retrieval of information. For a typical higher education institute, a huge amount of data is produced every day, originating from students, staff, administration and fiscal departments. Accreditation requirements and strategy execution performance indicators have to be extracted with tailor made on line analytical processing tools (OLAPs). The documentation process is a core while the cost is predefined with the allotted budget. Though the documentation process is usually highly standardized, building an integrated IT environment will minimize the cost and load on the staff and enable smooth strategic planning and implementation. Private cloud computing[7] data warehousing as a state of the art or business intelligence solutions will be a step towards strengthening the capabilities and tools at different hierarchies.

King Saud University is the largest and the oldest university in the Kingdom of Saudi Arabia, yet the leading in the Middle East. The university has 23 colleges and is serving more than 65000 students. The university budget is about two billion U.S. dollars for the year 2011. The university has an internal quality management system. The programs are accredited by various international accreditation institutions which differently require certain accreditation procedures and demand for different quality standards. This puts a huge load on the university staff and the university administration in monitoring the quality process and satisfying the requirement for each accreditation organization.

This paper shares authors' experience in planning for a data management model to be used for data collection in academic higher educational institutions. This intelligent educational information system (EIS) will allow the College of Computer and Information Systems at King Saud University, Saudi Arabia to use real-time decision support systems and to be provided with key performance indicators for monitoring performance. The paper also highlights differences between educational intelligence and business intelligence systems. Higher education implementation aspects ensuring suitable data query service to ease the running of high educational institutions are discussed and recognized. The aim is to share our experience in automated quality assurance systems. The college administration is assumed to follow up 
The rest of this paper is organized as follows: Model Consideration is described in section 2. The proposed model and its requirements are presented in section 3. In section 4 the managing team is listed. Proposed impacts and outcomes are addressed in section 5. Finally, the paper is concluded with a brief summary.

\section{Model Consideration}

The College for Computer and Information systems is one of the 23 colleges of King Saud University. College structure is shown in Figure 1.

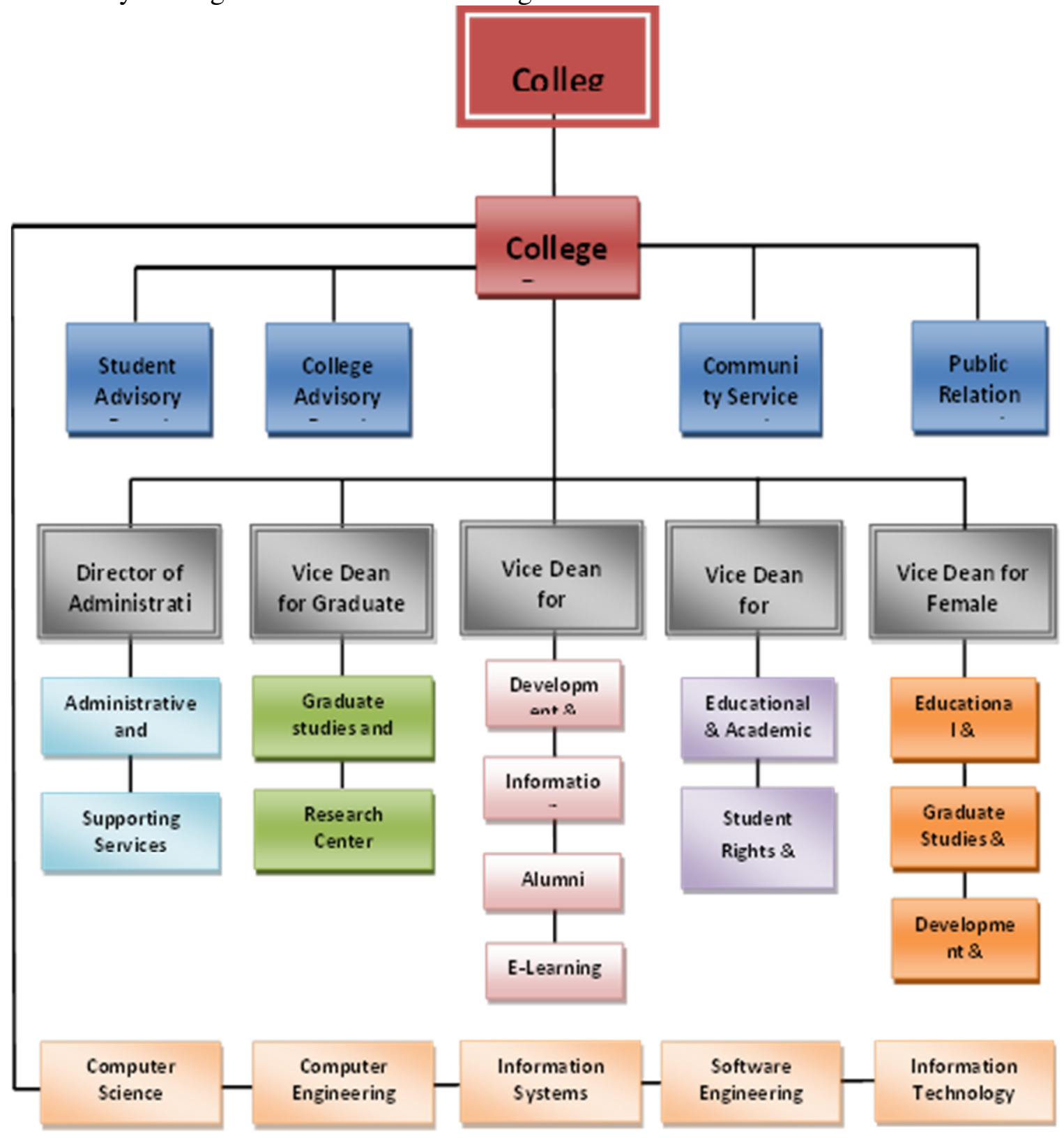

Figure 1: The CCIS college structure. 


\section{Proposed Quality Model}

The model considers an academic institution with a number of procedures related to the academic process. The goal of the proposed model is to analyze the current procedures in decision making at all levels and to provide a state of the art system for decision support which must be flexible and robust. Predefined quality requirements on each process are checked. Decisions are made based on the a reference benchmark for these requirements. Model restrictions include budgeting, existing infrastructure and human resources. The model components are outlined subsequently.

\subsection{Model Objectives}

The objectives for building an automated educational quality management system for an educational institution such as the College of Computer and Information Systems include:

1. Reducing time consumed in the follow-ups of administrative procedures

2. Providing documentation for the processes of decision making.

3. Facilitating a working environment for data warehousing business intelligence.

4. Providing a single version of the truth, and

5. Improving the quality and quantity of required data within optimal period of time.

\subsection{Strategies/Methods/Activities}

The model assumes a certain strategic plan with objectives, initiatives and activities. It is assumed that it should enable:

- Organizing for purpose.

- Activities:

- Full Survey: A full survey of all operations that issue reports for decision making

- Analysis: Analyze processes' inputs that are used to support decision making.

- Defining Data Sources: All sources along with their needed information and the related business processes should be defined.

\subsection{Methods required for implementation}

- Collecting data from all units and departments involved in decision making processes in the CCIS. These include:

- College Portal

- Students Affairs

- Admissions and Registration

- Development and Quality

- Graduate Studies

- Scientific Research

- Faculty Affairs

- Personnel Affairs

- Warehouses

- Administration and Management 
- Analyse the collected data and define the sequence flow needed for decision making.

- Create the request for proposal (RFP).

\subsection{Phases and Actions}

The model could be implanted in a single phase or split into a number of phases. Actions include:

- Conducting surveys.

- Analysing Data

- Creating RFP

\subsection{Model Evaluation}

This is made via key performance indicators with the following characteristics:

○ For survey

- Number of units involved.

- Number of processes per unit.

- For Analysis

- Number of processes where inputs are defined.

- Number of processes where PIs are defined.

○ For RFP

- Number of announcements

- Number of responses

\subsection{Interaction with the environment}

The model requires the following interaction at different institution levels:

- At the Department level

○ Providing data from the following units

- Department Portal

- Graduate Studies

- Scientific Research

- Personnel Affairs

- Warehouses

- Administration and Management

- At the college level

- Providing data from the following units

- Dean's office

- Vice-deans' offices

- Admissions and Registration

- Students Affairs

- College Units

- Faculty Affairs

- Administration and Management

- Personnel Affairs 
- At the university level

○ Providing data on the following items

- Updated university structure

- Updated decisions of the university council concerning the college.

- Set of governing academic, administrative and development

- College budget details.

- Human resources details.

\section{Managing Team}

The management team structure is shown in figure 1. It includes a chair person and his assisting director, a decision support system consultant, and two teams for quality control and data warehousing development.

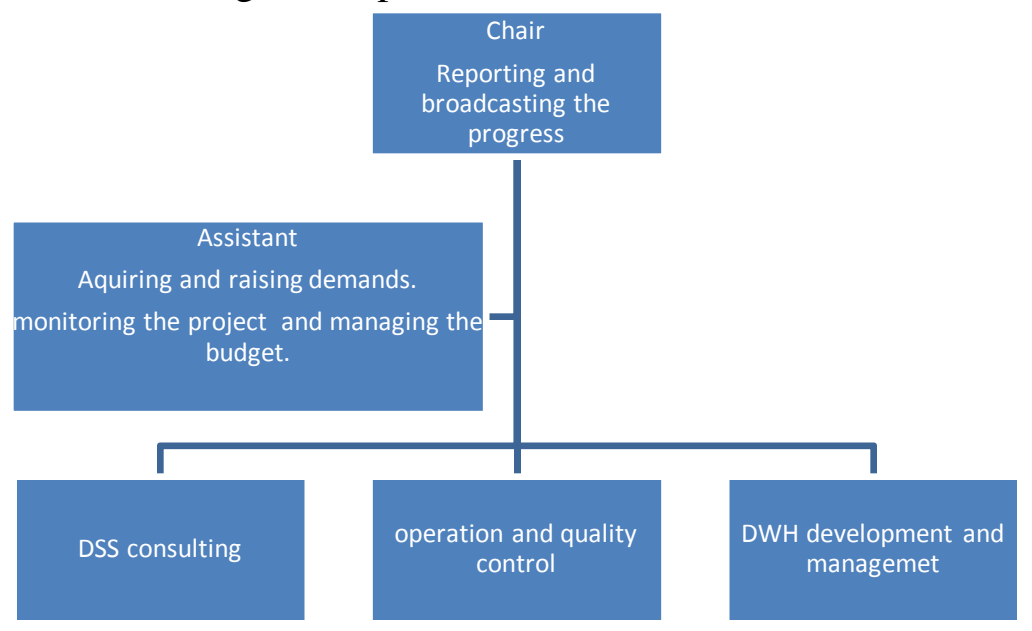

Figure 2: management team model architecture

\section{Possible Impacts and Outcomes}

The implemented model shall witness the following impacts and outcomes:

- A clear vision of the requirements and technical specifications of the required decision support system is expected.

- A clear state of the art request for proposal (RFP) for the proposed data warehouse is obtained.

- A rough estimation of the cost and requirements for establishing a data warehouse is delivered.

- Proposal for enhancement of administrative routine processes is delivered.

- END Results: Working environment for data warehousing business intelligence at the college level.

And shall consider the following changes which may occur during its implementation

- Readiness for using data warehousing

- Enhancement in the documentation procedures.

- Development in the strategic plan of the university and the CCIS College.

- Technology enhancement. 


\section{Summary}

In this work, a simplified quality management model for intelligent higher education institution has been suggested. The model was highlights the idea of integrating information systems with higher education environments based on structured and nonstructured clouds of dynamic repositories. Differences between Educational intelligence and business intelligence systems have been addressed. High education implementation aspects ensuring suitable data query service to ease the running of high educational institutions have been discussed and recognized. The implemented system will be a key benchmark for an educational institution where experiences are exploited and decisions are real-time supported. The outcomes of this model will prepare the institution information flow and resources for easy, cost effective and less head counts.

\section{References:}

1. Guster D. The application of business intelligence to higher education: Technical and managerial perspectives. J. of Information Technology Management volume XXIII, number 2, 2012.

2. Devlin, B.: Data warehouse: from architecture to implementation; Reading 1997.

3. Kimball, R.; Reeves, L.; Ross, M.; Thornthwaite, W.: The data warehouse lifecycle toolkit - Expert methods for designing, developing and deploying data warehouses; New York 1998.

4. Klesse, M.; Winter, R: Organizational Forms of Data Warehousing: An Explorative AnalysisProceedings of the 40th Hawaii International Conference on System Sciences 2007.

5. Watsona, H. J; Fullerb, C.; and Ariyachandraa , T.: Data warehouse governance: best practices at Blue Cross and Blue Shield of North Carolina. Decision Support Systems 38 (2004) 435-450.

6. McKendrick,, J.:Oracle IOUG group: A new dimension to data warehousing: 2011 IOUG data warehousing survey. Unisphere Research

7. Madsen, M: Technology White Paper. Cloud Computing Models for Data Warehousing Third Nature Inc., 2012. 